\title{
Mycotic Keratitis in Patients Attending a Tertiary Care Hospital
}

\author{
Sri Vaishnavi Renukuntla*, Nisha Karanje and Sakshi Ravikanth Patil \\ Bharati Vidyapeeth Medical College and Hospital, Sangli- 416414, Maharashthra, India \\ *Corresponding author
}

\section{A B S T R A C T}

\begin{tabular}{|c|c|}
\hline Keywords & \multirow{4}{*}{$\begin{array}{l}\text { The research was done to isolate the common fungal agent involved in } \\
\text { mycotic keratitis attending tertiary care hospital. The purpose of isolating } \\
\text { the organisms is for the early diagnosis and treatment of the patients. The } \\
\text { research lead to the finding that, Corneal trauma was the most common } \\
\text { predisposing factor in the pathogenesis of mycotic keratitis, which was } \\
\text { mostly seen in farmers i.e, agriculturists who are in the actively working } \\
\text { age group.. Aspergillus species was the commonest agent isolated by slide } \\
\text { culture, it includes A. flavus, A. fumigatus and A. niger. Methods such as } \\
\text { KOH mount and Gram staining are useful in the early diagnosis and } \\
\text { treatment of corneal ulcer. }\end{array}$} \\
\hline $\begin{array}{l}\text { Mycotic keratitis, } \\
\text { corneal trauma, } \\
\text { Aspergillus species, } \\
\text { KOH mount, slide } \\
\text { culture }\end{array}$ & \\
\hline Article Info & \\
\hline & \\
\hline
\end{tabular}

\section{Introduction}

Ophthalmic infections are regarded as among the chief causes of ocular morbidity and mortality worldwide. A larger proportion of keratitis is reported from developing countries than in developed countries.

The aetiological agents implicated are fungi, bacteria and protozoan. While viral infections are the leading cause of corneal ulcer in developed nations, bacteria, fungi, acanthamoeba and chlyamidia are important aetiological agents in the developing world. It is therefore very important to recognise the prevalence and aetiology of keratitis. ${ }^{[2]}$

Mycotic keratitis is an infection caused by fungus that leads to inflammation and ulceration, usually following trauma or treatment for a bacterial infection with steroids or antibiotics. $^{[1]}$

In mycotic keratitis, two types have been recognised: Keratitis due to filamentous fungi (especially Fusarium and Aspergillus), which commonly occurs in tropical and subtropical zones, and associated with corneal trauma (and concurrent contamination with plant material); and Keratitis due to yeast-like and related fungi particularly Candida. ${ }^{[2]}$

Fungal keratitis can cause a deep and severe corneal ulcer. It is caused by Aspergillus spp., Fusarium spp., Candida spp., Rhizopus, Mucor, and other fungi. The typical feature of fungal infection is slow onset and gradual progression, where signs are much more than 
symptoms. Small satellite lesions around the ulcer are a common feature of fungal keratitis and hypopyon is usually seen. ${ }^{[1]}$

The typical features suggestive of fungal infection are feathery edges or a dry, gray, elevated infiltrate and satellite lesions. ${ }^{[2]}$

Complications of keratitis include secondary glaucoma, corneal scarring, perforation, corneal opacity, corneal thinning, uveitis, severe anterior chamber reaction, severe vision loss and loss of eye. ${ }^{[2]}$

\section{Materials and Methods}

The research includes a prospective study which was conducted over a span of 2 months $\left(1^{\text {st }}\right.$ July 2016 to $31^{\text {st }}$ August 2016). It included all the IPD and OPD patients attending Ophthalmology department, Bharati Vidyapeeth Deemed University, Medical College and Hospital, Sangli.

The study subjects where the patients attending Ophthalmology OPD with history of corneal ulceration/trauma.

\section{Inclusion criteria}

Clinically suspected cases of corneal ulcers.

\section{Exclusion criteria}

Bacterial keratitis

Viral keratitis

Parasitic keratitis

Autoimmune keratitis

\section{Materials}

$10 \% \mathrm{KOH}$

Gram stain

Sabouraud dextrose agar

Blood agar

Microscope
LPCB (Lactophenol Cotton Blue Mount) Fungal Slide Culture.

\section{Procedure}

Detailed history was taken of all clinically suspected cases.

In all cases, corneal scrapings were aseptically collected direct from the base and margins of ulcers using kimura spatula under direct vision through slit lamp after instillation of anesthetic eye drops.

Direct microscopy was done under $10 \% \mathrm{KOH}$ examination and Gram staining.

Corneal material was inoculated onto blood agar and Sabourauds dextrose agar in the form of $\mathrm{C}$ streak; only growth occurring on the $\mathrm{C}$ streaks was considered to be significant.

All the media was incubated at $37^{\circ} \mathrm{C}$ and $25^{\circ} \mathrm{C}$ for a period of four weeks.

Any growth present on the media was identified by standard laboratory tests viz. the rate of growth, colony morphology and microscopic appearance in lactophenol cotton blue mount and slide culture.

\section{Statistics}

The percentage of each fungal strain causing keratitis was obtained as shown in the table 2.

The sensitivity and specificity of the investigations was done (Table 3).

\section{Results and Discussion}

The study was conducted in the department of Microbiology and Ophthalmology for a period of two months (June 2016 - August 2016) in our hospital. Out of 31 cases of corneal ulcers investigated, Mycotic keratitis 
was observed in 17 patients, 6 patients had bacterial growth, 3 had Acanthamoeba species growth, 3 had mixed growth and 2 were culture negative (Table 1).

Of the 17 culture positive cases of fungi, the most frequently isolated agent was Aspergillus species i.e., A.flavus (6 cases), A. fumigates (5 cases), A. niger (2 cases). Followed by Fusarium solani (2 cases), Mucor (1 case), Penicillium (1 case) (Table 2).

Ocular trauma appeared to be the most common predisposing factor in our study, several other factors such as surgery for cataract, use of contact lens also contribute in the pathogenesis of Mycotic keratitis (Table 2).

Normally cornea is highly resistant to mycotic infections. In spite of its remarkable ability to repair itself after injury, a large number of cases are seen suffering from keratomycosis, the reason behind, is the negligence of the patient and improper management of injury. Mycotic keratitis continues to be an important cause of ocular morbidity even after a lot of advances in the ocular treatment strategies. In tropical countries such as India, mycotic keratitis is the most frequently encountered fungal infection.

The incidence of fungal keratitis in this study was $54.8 \%$, which is much higher than the incidence in the study done by Kalshetti et al., ${ }^{[6]}$ this difference is due to regional variation, as fungal keratitis is expected to be more common in the tropical and subtropical region than in the temperate region.

Incidence of fungal ulcers was more in males $(70.5 \%)$ than in females $(29.5 \%)$. This study result coincides with the study of other workers ${ }^{[1,2,3,6,8]}$. Higher incidence of keratitis in males can be attributed to more outdoor activity of males in field activities related to agriculture and farming.

Table.1 Predisposing factor and number of cases with mycotic keratitis

\begin{tabular}{|l|c|c|}
\hline Predisposing Factor & \multicolumn{2}{|c|}{ Number of cases } \\
\hline & Total number of cases studied & No. of positive cases for Fungus \\
\hline History of corneal trauma & 17 & 13 \\
\hline Topical antibiotic/steroids & 3 & 0 \\
\hline Surgery (Cataract) & 7 & 3 \\
\hline Use of Herbal Medicine & 0 & 0 \\
\hline Use of contact lens & 4 & 1 \\
\hline Local conditions & 0 & 0 \\
\hline Systemic conditions & 0 & 0 \\
\hline No significant History & 0 & 0 \\
\hline
\end{tabular}

Table.2 Type of isolated fungal species

\begin{tabular}{lll}
\hline Type of Fungus & Isolated species & Numbers \\
\hline Filamentous moulds & Aspergillus flavus & 6 \\
& Aspergillus fumigates & 5 \\
& Aspergillus niger & 2 \\
Fusarium solani & 2 \\
& Mucor & 1 \\
& Penicillium & 1 \\
\hline
\end{tabular}


Table.3 Comparative study of microbiological investigation

\begin{tabular}{|c|c|c|c|c|c|c|c|}
\hline $\begin{array}{l}\text { SR } \\
\text { no. }\end{array}$ & $\begin{array}{l}\text { Name of the } \\
\text { investigation }\end{array}$ & Results & No. & \multicolumn{2}{|c|}{$\begin{array}{l}\text { Presence of fungal } \\
\text { growth in culture } \\
\text { (SDA and BA*) } \\
\text { positive negative }\end{array}$} & $\begin{array}{l}\text { Sensitivity } \\
(\%)\end{array}$ & $\begin{array}{l}\text { Specifity } \\
(\%)\end{array}$ \\
\hline 1 & $\begin{array}{l}\text { Detection of } \\
\text { fungal } \\
\text { filaments in } \\
10 \% \mathrm{KOH} \\
\text { smear }\end{array}$ & $\begin{array}{l}\text { Positive } \\
\text { Negative } \\
\text { Total }\end{array}$ & $\begin{array}{l}13 \\
18 \\
31\end{array}$ & $\begin{array}{c}10 \\
7 \\
17\end{array}$ & $\begin{array}{l}3 \\
11 \\
14\end{array}$ & $58.82 \%$ & $78.57 \%$ \\
\hline 2 & $\begin{array}{l}\text { Detection of } \\
\text { fungal } \\
\text { filaments in } \\
\text { Gram } \\
\text { stained } \\
\text { smear }\end{array}$ & $\begin{array}{l}\text { Positive } \\
\text { Negative } \\
\text { Total }\end{array}$ & $\begin{array}{l}12 \\
19 \\
31\end{array}$ & $\begin{array}{c}12 \\
5 \\
17\end{array}$ & $\begin{array}{c}0 \\
14 \\
14\end{array}$ & $70.58 \%$ & $100 \%$ \\
\hline 3 & $\begin{array}{l}\text { Clinical } \\
\text { suspicion of } \\
\text { fungal } \\
\text { keratitis on } \\
\text { slit lamp } \\
\text { examination }\end{array}$ & $\begin{array}{l}\text { Positive } \\
\text { Negative } \\
\text { Total }\end{array}$ & $\begin{array}{l}14 \\
17 \\
31\end{array}$ & $\begin{array}{c}11 \\
6 \\
17\end{array}$ & $\begin{array}{l}3 \\
11 \\
14\end{array}$ & $64.70 \%$ & $78.57 \%$ \\
\hline
\end{tabular}

Fig.1 KOH mount - Septate hyphae of Aspergillus species

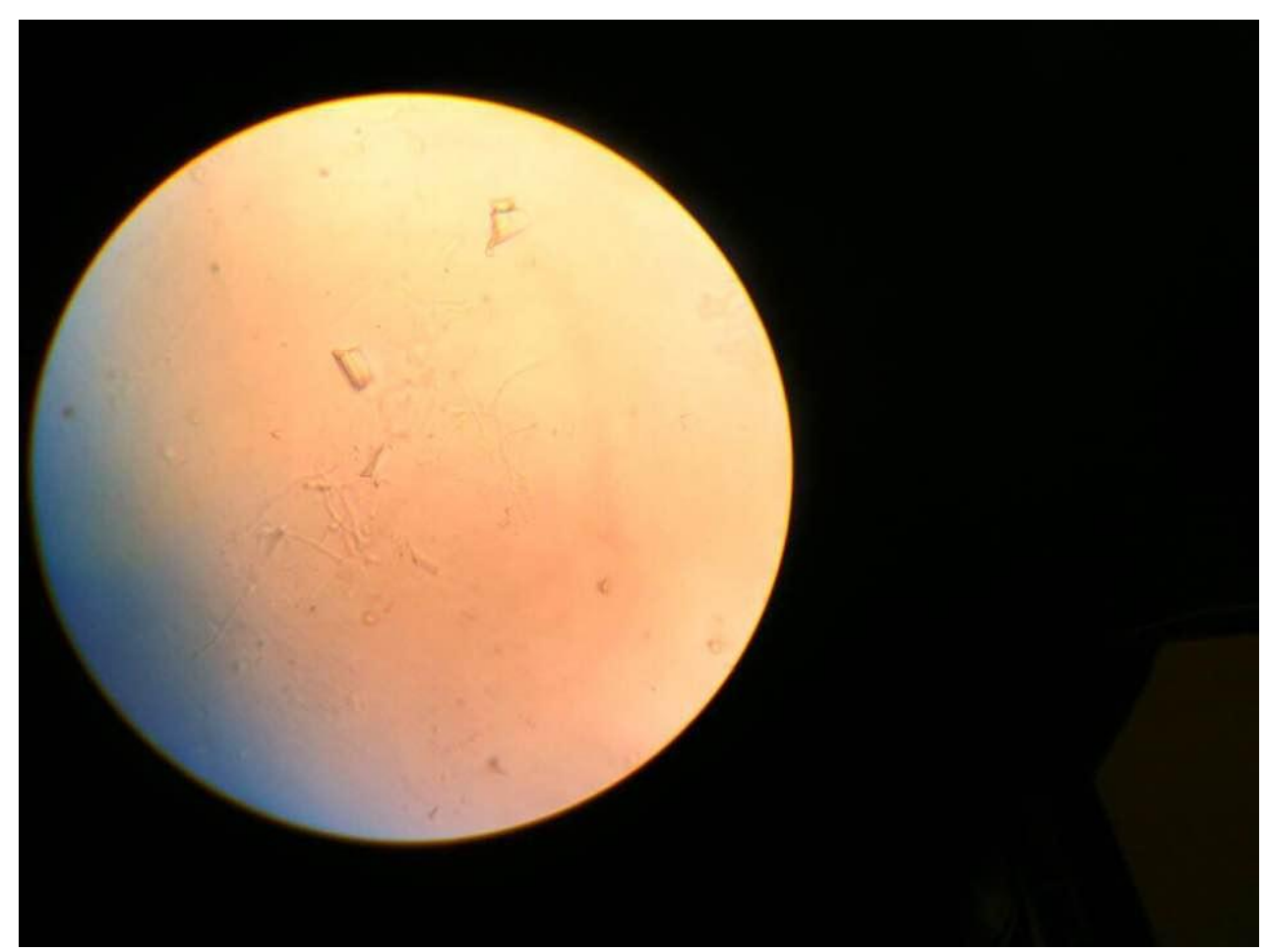


Fig.2 Gram stain - Aspergillus species

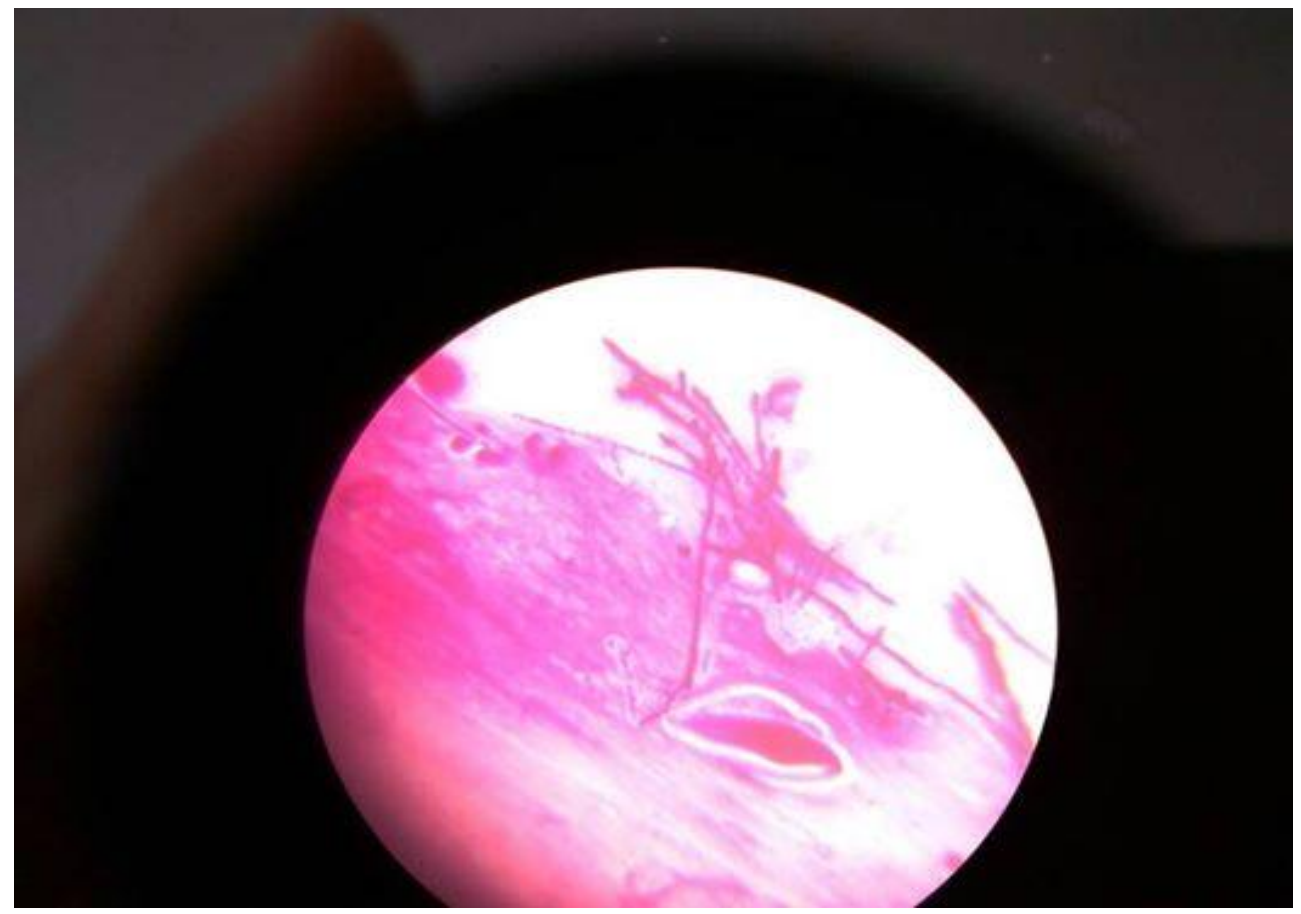

In our study, majority of the fungal ulcers were diagnosed in the age group of 21-40 years. This is the most common actively working age group. ${ }^{[1,2,3,6] \text {. }}$

Ocular trauma was the most common factor in predisposition of mycotic keratitis, as is seen in the other studies $[1,2,3,6,8]$. Trauma by vegetative material was believed to be a specific risk factor for a fungal infection of cornea. Other predisposing factors include topical antibiotics/steroids, surgery for cataract and use of contact lens (Table 1). Agriculturists were more commonly affected by mycotic keratitis in our study. Similar observations were made in other studies made by Tilak et al., Gupta et al., Bharati et al., and Kalshetti et al., ${ }^{[1,2,3,6]}$

Aspergillus species was the most commonly isolated agent, which is similar to the studies done by Tilak et al., Kalsetti et al., ${ }^{[1,2,4,6]}$. In some other studies Fusarium species was identified as the most common agent causing mycotic keratitis ${ }^{[3]}$ (Table 2).
In the cases were Acanthamoeba was found the causative agent for keratitis, there was a history of bathing in a pond in 1 case and history of usage of contact lens in the other 2 cases. ${ }^{[2]}$

The sensitivity and specificity of clinical diagnosis of fungal keratitis made by an ophthalmologist using a slitlamp biomicroscope was $64.70 \%$ and $78.57 \%$ respectively, which was considered lower than the result obtained from other study of Bharati et al., ${ }^{[3]}$. This difference was because the study done by Bharati et al., had a large sample size and a long research period. There was a strong agreement between the results obtained by microbiologist (KOH smear) and Ophthalmologist (slit lamp examination), Kappa $=0.934$ at $\mathrm{P}=0.064$ which means, that observed agreement between the two is not merely by chance (Table 3, Figs. 1 and 2).

Mycotic keratits is usually treated with a topical antifungal agent. Natamycin, a polyene is considered the drug of choice for 
filamentous fungi. Econazole, a triazole has similar effect as that of natamycin against filamentous fungi. Voriconazole works for Candida spp, Aspergillus spp, Scedophorium, Fusarium, Paecillomyces spp. Amphotericin B covers Candida and Aspergillus spp.

\section{Acknowledgments}

I express my deep gratitude to my respected teacher and guide Dr. Nisha Karanje, Ass. Professor; Dr. Sakshi Ravikanth Patil, Associate. Professor, Department of Ophthalmology; Dr. Shubhangi Gadgil, Professor and Head, Department of Microbiology; Dr. Anil Kulkarni, Professor and Head, Department of Ophthalmology; Dr. RB Kulkarni, Dean, Bharati Vidyapeeth Medical College and Hospital, Sangli for the Approval of this study. I am thankful to all the teachers and all the nonteaching staff in the department of Microbiology for their kind support.

\section{References}

1. Raginitilak, Abhisek Singh, Mycotic keratitis in India: a five year retrospective study. J Infect Devctries
2010; 4(3):171-174.

2. A Gupta, MR Capoor,Clinicodemographical profile of keratomycosis in Delhi, North India. Indian Journal of Medical Microbiology, (2014) 32(3):310-314.

3. MJayaharBharathi, Msc; R Ramakrishnan, MS, Epidemiological Characteristics and Laboratory Diagnosis of fungal Keratitis. A Three-year study. Indian J Ophthalmol 2003;51:315-21.

4. Anita Panda, Madan Mohan, Mycotic keratitis in Indian patients. Indian Journal of Ophthalmology.(1984) ;32:311-315.

5. Varsha TukaramKalshetti, Surendra P. wadgaonkar, Microbiological evaluation of mycotic keratitis in north Maharasthra, India: A prospective study. Journal of Microbiology and Infectious Diseases/ JMID. 2015;5(3):99-102.

6. MRCapoor. A Gupta, Clinico-dermographical profile of keratomycosis in Delhi, North India. Indian Journal of Medical Microbiology. 2014;32:310314.

\section{How to cite this article:}

Sri Vaishnavi Renukuntla, Nisha Karanje and Sakshi Ravikanth Patil. 2017. Mycotic Keratitis in Patients Attending a Tertiary Care Hospital. Int.J.Curr.Microbiol.App.Sci. 6(10): 1665-1670. doi: https://doi.org/10.20546/ijcmas.2017.610.201 